\title{
Impact evaluation of the Northern Fruit and Vegetable Pilot Programme - a cluster-randomised controlled trial
}

\author{
Meizi He ${ }^{1,2 *}+$, Charlene Beynon ${ }^{1}$, Michelle Sangster Bouck ${ }^{1}$, Renée St Onge ${ }^{1}$, \\ Susan Stewart ${ }^{1}$, Linda Khoshaba ${ }^{1}$, Betty A Horbul ${ }^{3}$ and Bill Chircoski ${ }^{3}$ \\ ${ }^{1}$ Public Health Research, Education and Development (PHRED) Programme, Ontario, Canada: ${ }^{2}$ Department of \\ Health and Kinesiology, University of Texas at San Antonio, One UTSA Circle, San Antonio, TX, USA: \\ ${ }^{3}$ Porcupine Health Unit, Ontario, Canada
}

Submitted 17 November 2008: Accepted 8 April 2009: First published online 28 May 2009

\begin{abstract}
Objective: The purpose of this impact evaluation was to measure the influence of a government of Ontario, Canada health promotion initiative, the Northern Fruit and Vegetable Pilot Programme (NFVPP), on elementary school-aged children's psychosocial variables regarding fruit and vegetables, and fruit and vegetable consumption patterns.

Design: A cluster-randomised controlled trial design was used. The NFVPP consisted of three intervention arms: (i) Intervention I: Free Fruit and Vegetable Snack (FFVS) + Enhanced Nutrition Education; (ii) Intervention II: FFVS-alone; and (iii) Control group. Using the Pro-Children Questionnaire, the primary outcome measure was children's fruit and vegetable consumption, and the secondary outcome measures included differences in children's awareness, knowledge, self-efficacy, preference, intention and willingness to increase fruit and vegetable consumption. Setting/Subjects: Twenty-six elementary schools in a defined area of Northern Ontario were eligible to participate in the impact evaluation. A final sample size of 1277 students in grades five to eight was achieved.

Results: Intervention I students consumed more fruit and vegetables at school than their Control counterparts by 0.49 serving/d $(P<0.05)$. Similarly, Intervention II students consumed more fruit and vegetables at school than Control students by 0.42 serving/d, although this difference was not statistically significant. Among students in both intervention groups, preferences for certain fruit and vegetables shifted from 'never tried it' towards 'like it'.

Conclusions: The NFVPP resulted in positive changes in elementary school-aged children's fruit and vegetable consumption at school, and favourable preference changes for certain fruit and vegetables.
\end{abstract}

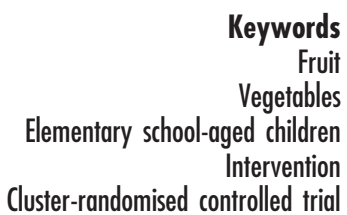

Obesity and chronic diseases such as CVD, cancer and type 2 diabetes are major public health concerns. Unhealthy eating and physical inactivity are key contributors to the prevalence of obesity and chronic diseases, and thus are of public health importance. Fruit and vegetables are important components of a healthy diet. The 2004 Canadian Community Health Survey reported that children and youth who eat fruit and vegetables five or more times a day are substantially less likely to be overweight or obese, than those whose fruit and vegetable consumption is less frequent ${ }^{(1)}$. Fruit and vegetables also help prevent chronic diseases such as CVD and certain cancers if consumed daily, in sufficient amounts ${ }^{(2,3)}$. Health Canada's Food Guide recommends that children

$\dagger$ Dr Meizi He was an Associate Professor with Brescia University College at the time the study was conducted. aged 4-13 years consume five to six servings of fruit and vegetables every day ${ }^{(4)}$. Unfortunately, Canadian children and youth, on average, consume only 4.5 servings of fruit and vegetables/d, and seven out of ten do not consume the recommended number of daily servings ${ }^{(5)}$.

Increasing fruit and vegetable consumption among children and youth is an important public health approach ${ }^{(6)}$, because dietary habits developed early in life may persist throughout adulthood ${ }^{(7,8)}$. Children spend a large portion of their days in school; thus, schools are key settings for delivering programmes aimed at children and adolescents ${ }^{(9)}$. Canadian schools do not have a federally assisted meal programme like the National School Lunch Program in the United States ${ }^{(10)}$, and there are no cafeterias in Ontario elementary schools. Offering free fruit and vegetables during school hours provides a promising opportunity to promote healthy eating in a Canadian setting. 
In 2006, as part of Ontario's Action Plan for Healthy Eating and Active Living, the Ontario (Canada) Ministry of Health Promotion launched the school-based Northern Fruit and Vegetable Pilot Programme (NFVPP), which provided free fruit and vegetables to students in selected elementary schools in a defined area of Northern Ontario. The primary mandate of the NFVPP was to promote healthy eating and wellness while increasing children's awareness of the benefits of eating fruit and vegetables. The programme's specific objectives were to increase awareness of the dietary importance of fruit and vegetables, favourably shift children's preferences and willingness to try fruit and vegetables and increase consumption of fruit and vegetables, both in and outside of school.

A rigorous evaluation was conducted to assess the implementation process (i.e. process evaluation) and the impact (i.e. impact evaluation) of the NFVPP. The present paper focuses on results from the impact evaluation, while findings from the process evaluation will be reported in a separate paper ${ }^{(11)}$. The impact evaluation's objectives were to assess the effect of the NFVPP on psychosocial variables regarding fruit and vegetable behaviours, and fruit and vegetable consumption patterns.

\section{Experimental methods}

The evaluation protocol was approved by the Research Ethics Boards at Brescia University College and The University of Western Ontario, London, Ontario, Canada. Parental informed consent was obtained prior to data collection.

\section{Northern Fruit and Vegetable Pilot Programme (NFVPP)}

The NFVPP, a 21-week programme for elementary-school children in seven Northern Ontario communities, consisted of two components: (i) Free Fruit and Vegetable Snacks (FFVS) and (ii) Enhanced Nutrition Education (ENE). The FFVS offered either one fruit or one vegetable serving three times per week, to every student in junior kindergarten to grade eight in all intervention schools. The FFVS menu was structured on a 3 -week rotation, with a total of nine items (e.g. carrot sticks, broccoli florets, whole pear fruit cups, etc.). The ENE, entitled 'Paint Your Plate! Create a Masterpiece: Vegetables and Fruit Action Guide for Schools', was a comprehensive curriculumbased resource for teachers to incorporate into the classroom. Activities were to be used at the school and community level to promote fruit and vegetables, and included various activities for each grade. Schools were encouraged to use the resource kit's nutritional education materials for morning announcements and school newsletters. Intervention integrity was assessed through a process evaluation, the results of which will be reported in a separate paper ${ }^{(11)}$.

\section{Study design and sample size calculation}

A non-blinded, cluster-randomised controlled trial (RCT) design was used with schools as the unit of measurement (clusters). Schools were allocated randomly into one of three intervention arms: (i) Intervention I: FFVS+ENE; (ii) Intervention II: FFVS-alone; and (iii) Control group: no intervention. Routine school-based nutrition education activities were carried out according to the gradelevel curriculum in the Intervention II and Control groups. Assuming that there would be thirty students in each class and that, based on a similar study's findings, the intra-class correlation coefficient (ICC) of fruit and vegetable consumption among elementary children in the same school (cluster) is $0.03^{(5)}$, a sample size of 437 students per intervention arm was required to detect an anticipated intervention effect of $0 \cdot 4$ fruit and vegetable serving/d, with a statistical power of $80 \%$ and a twosided significance level (type- 1 error) of $0 \cdot 05$. The present study could not be blinded because the community knew the components of the intervention; thus, researchers were unable to prevent study subjects from knowing what intervention strategies they were receiving.

\section{Subjects}

While all students in the intervention schools were exposed to the intervention, impact evaluation data were only collected from students in grades five to eight, due to the required literacy level for filling out the survey.

\section{Sample allocation and sampling scheme}

Elementary schools from four school boards in the Porcupine region were invited to participate voluntarily in the NFVPP. All thirty-two schools agreed to participate, however six did not have grades five to eight. These schools were eliminated from the impact evaluation, and the remaining twenty-six schools were included. Using the SPSS for Windows statistical software package version 15.0 (SPSS Inc., Chicago, IL, USA), the eligible schools were allocated randomly into Intervention I (nine schools), Intervention II (nine schools) or the Control group (eight schools). Of the 2254 grade five to eight students in the eligible schools, 1586 participated (70.4\% response rate) at baseline, and 1277 completed the survey at the end of the evaluation (19.5\% dropout rate), for a final completion rate of $56 \cdot 6 \%$ (Fig. 1).

\section{Outcome measures}

The primary outcome measure was the difference in children's fruit and vegetable consumption, in the presence and absence of the intervention. Secondary outcome measures included changes in children's fruit and vegetable awareness, knowledge and preferences, as well as their willingness and self-efficacy to increase fruit and vegetable consumption, with or without the intervention. The pre-coded $24 \mathrm{~h}$ fruit and vegetable recall questionnaire $^{(12)}$ asked about fruit and vegetable intake 


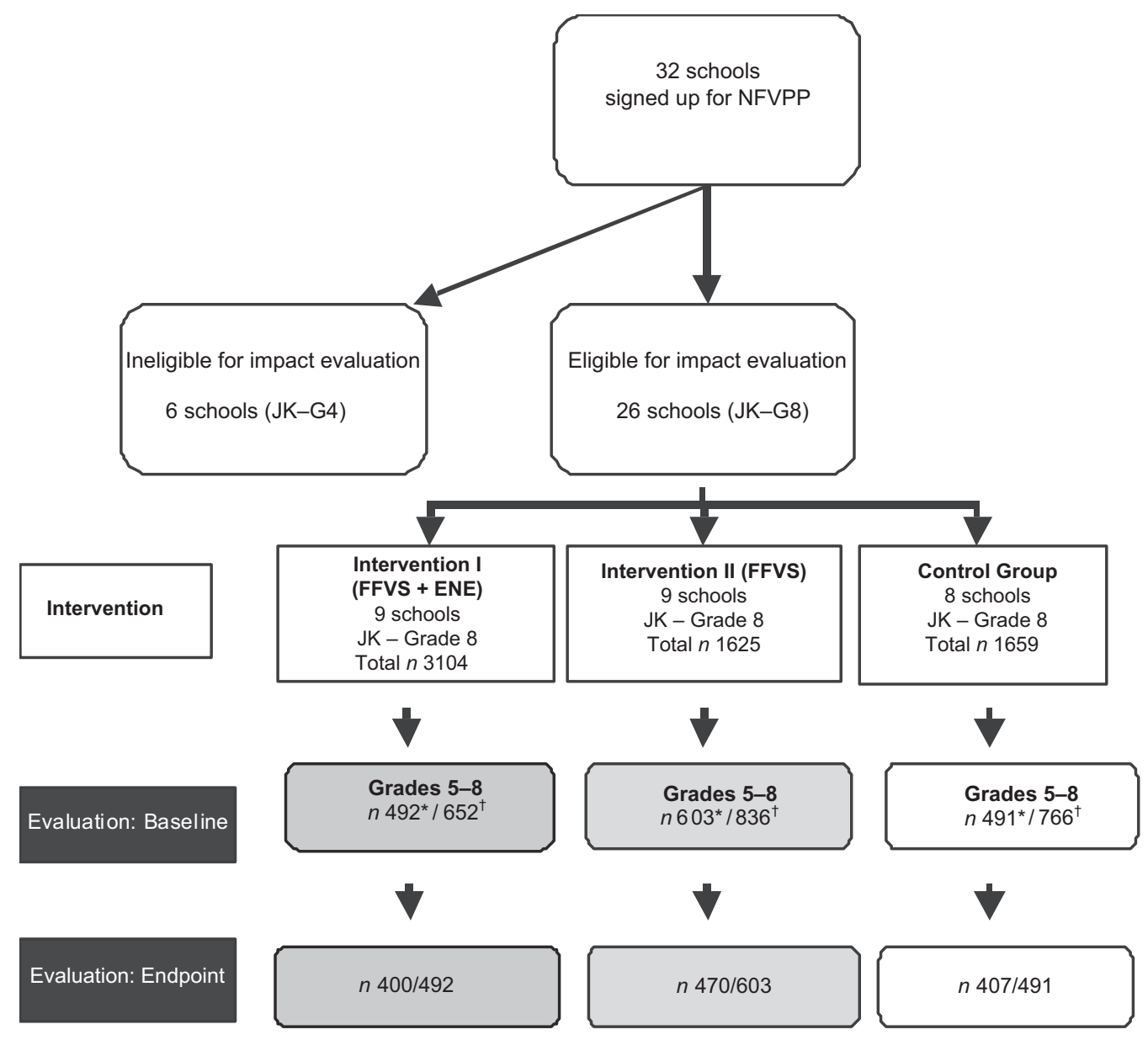

Fig. 1 Study design and sample scheme *Participating subjects; †eligible subjects; NFVPP, Northern Fruit and Vegetable Pilot Programme; JK, junior kindergarten; G, grade

during: morning before school; at school; afternoon after school; at dinner; and evening after dinner. For each interval, participants recorded their juice, fruit and raw vegetable intake. Salad and vegetable soup consumption were only assessed for lunch, afternoon after school, dinner and evening after dinner, while intake of cooked vegetables was assessed for the three after-school intervals only. Amounts were indicated in terms of the number of pieces, slices or glasses consumed, and standards for each were defined. Fruit and vegetable items and standard amounts in the questionnaire were modified to reflect Northern Ontario customs and terminology. Children's awareness, knowledge and preferences with regard to fruit and vegetable consumption were measured using an instrument adapted from the Pro-Children Questionnaire ${ }^{(13)}$. Both instruments were previously validated, and shown to be sensitive and reliable for measuring intervention effects ${ }^{(12,13)}$.

Data were collected at baseline and at the end of the intervention from participants in the three intervention arms. Surveys were administered on Wednesdays, Thursdays and Fridays during the data collection period in order to obtain a weekday $24 \mathrm{~h}$ dietary recall that coincided with the Tuesday, Wednesday and Thursday FFVS distribution days; however, schools may have deviated from these set distribution dates due to bad weather. While a full serving was provided to students on the FFVS days, every student may not have eaten the snack provided. The questionnaire was administered to students in their classrooms, and was completed by the children (with assistance from teachers) after the teachers gave brief instructions scripted by the researchers. Students were encouraged to complete the survey without discussion with their peers. All aspects of the evaluation were conducted in English and French.

All quantitative data were analysed using SPSS. Missing values were excluded listwise. The level of significance for all statistical tests was set at 0•05. The 'intent-to-treat' analysis principle was followed, and the GLM Univariate procedure was used to determine intervention effects. Because the study design consisted of schools as the unit of measurement (clusters) and students as the unit of analysis, cluster effects were accounted for in the analyses. The models included the random effect of schoolwithin-condition to account for the clustering effect, where outcome measures were the dependent variables, 
the intervention was the fixed factor and individual-level factors (i.e. the corresponding outcome measures at baseline, gender and age) were covariates. School-level factors (i.e. urban $v$. rural) and pre-existing fruit and vegetable programmes were included in the models as random factors. Children who had both baseline and endpoint values were included in the analysis for each variable. The intervention's effect size and SE were reported as the differences in outcome measures at endpoint with and without intervention, controlling for baseline values and other confounders.

\section{Primary outcome - fruit and vegetable intake}

Data from the $24 \mathrm{~h}$ recall were coded manually ${ }^{(12)}$. A coding protocol was developed, which categorised fruit, vegetables and $100 \%$ fruit juice by group and/or mixed food item based on the 2004 Dole 5-A-Day Fruit \& Vegetable Nutrition Facts Chart ${ }^{(14)}$. Serving sizes defined by this coding protocol were consistent with Canada's Food Guide to Healthy Eating ${ }^{(4)}$. Means and SD were calculated to describe children's fruit and vegetable consumption (servings/d). No clear guideline is currently available for classifying outliers in fruit and vegetable intake among adults or children. Fifteen servings per day has been used previously as the cut-off for adults ${ }^{(15)}$. Twelve servings was chosen as the cut-off for children in the current study. Students whose daily fruit and vegetable consumption exceeded twelve servings were considered outliers and excluded from the analyses related to fruit and vegetable intake. This included 227 cases at baseline and 223 at endpoint. Among these, eighty-five cases had an intake greater than twelve servings at both baseline and endpoint, which brought the total number of outliers to 365 . The average fruit and vegetable intake for these outliers at baseline and endpoint was $19 \cdot 2$ servings (SD 7.9) and $20 \cdot 4$ (SD 8.8), respectively. In addition, 217 cases had a missing value in total fruit and vegetable intake either at baseline or endpoint; therefore, the final sample size for the primary outcome analysis was 695.

\section{Secondary outcomes - psychosocial and bebavioural scales}

Scales on children's knowledge, attitude, liking, selfefficacy, intention, willingness, habit, preferences and peer influences towards fruit and vegetables were created based on the Pro-Children Questionnaire ${ }^{(5)}$. Potential individual cognitive and behavioural changes beyond these set scales were also explored; the $\chi^{2}$ test was used to compare, by group, students' responses to each of the psychosocial and behavioural questions at baseline and endpoint. This test was used because the Stuart-Maxwell test, which is used for paired categorical data that have more than two categories, is not available on SPSS.

\section{Results}

\section{Subjects}

Table 1 presents the schools' profiles by intervention arms. In general, school characteristics were similar across the three groups, except that Intervention I schools had more pre-existing fruit and vegetable programmes. This was considered a confounder and controlled for in all analyses to determine intervention effect. Subjects' profiles were, in general, similar across the three groups (Table 2). Baseline fruit and vegetable intake were not significantly different among the three groups $(F=2 \cdot 3, P=0 \cdot 1)$. The average intake was 4.6 servings/d, which is comparable to the recent national average daily fruit and vegetable intake among this age group (i.e. 4.5 and $4 \cdot 4$ servings for boys and girls, respectively) ${ }^{(16)}$.

\section{Participants' opinion on receiving free fruit and vegetables}

At baseline, over $80 \%$ of students across the three groups liked the idea of receiving free fruit at school (Table 3). Student responses stayed almost the same at endpoint. At baseline, $60 \%$ to $70 \%$ of students liked the idea of receiving free vegetables, and the percentages remained relatively stable at endpoint.

\section{Intervention effect}

Primary outcome - fruit and vegetable intake

Table 4 shows intervention effects on fruit and vegetable intake (servings/d). Intervention I and II groups had higher total fruit and vegetable intake than the Control group ( 0.6 and 0.5 serving/d, respectively), although the differences were not statistically significant. However, Intervention I students consumed statistically more fruit and vegetables at school $(0.49$ serving/d, $P<0.05)$ than students in the Control group (Fig. 2). Similarly, Intervention II students consumed $0 \cdot 42$ serving/d $(P>0 \cdot 05)$ more at school than Control students; however, this

Table 1 School profile by intervention arm $(n)$

\begin{tabular}{lccc}
\hline & Intervention I $(n$ 9) & Intervention II $(n$ 9) & Control group $(n$ 8) \\
\hline School location (urban/rural) & $5 / 4$ & $6 / 3$ & $5 / 3$ \\
School language (English/French) & $5 / 4$ & $5 / 4$ & $4 / 4$ \\
School Boards (Public/Catholic) & $4 / 5$ & $4 / 5$ & $3 / 5$ \\
Presence of existing FV programme (yes/no) & $3 / 6$ & $1 / 8$ & $0 / 8$ \\
Consent process (active/passive) & $6 / 3$ & $6 / 3$ & $5 / 3$ \\
\hline
\end{tabular}

FV, fruit and vegetable. 
Table 2 Subject profile by intervention arm (n)

\begin{tabular}{|c|c|c|c|c|c|c|c|c|}
\hline & \multicolumn{2}{|c|}{ Intervention I (final $n$ 400) } & \multicolumn{2}{|c|}{ Intervention II (final $n$ 470) } & \multicolumn{2}{|c|}{ Control group (final $n$ 407) } & \multicolumn{2}{|c|}{ Total (final $n$ 1277) } \\
\hline & Mean or $n$ & SD or $\%$ & Mean or $n$ & SD or $\%$ & Mean or $n$ & SD or $\%$ & Mean or $n$ & SD or $\%$ \\
\hline Age (years) (mean (SD)) & $11 \cdot 5$ & $1 \cdot 2$ & $11 \cdot 8$ & $1 \cdot 3$ & $11 \cdot 6$ & $1 \cdot 2$ & $11 \cdot 6$ & $1 \cdot 2$ \\
\hline \multicolumn{9}{|l|}{ Gender } \\
\hline Girl & 228 & $\begin{array}{l}43 \\
57\end{array}$ & $\begin{array}{l}2<4 \\
246\end{array}$ & $52 \cdot 3$ & $\begin{array}{l}180 \\
227\end{array}$ & $\begin{array}{l}44 \cdot 2 \\
55 \cdot 8\end{array}$ & $\begin{array}{l}576 \\
701\end{array}$ & $\begin{array}{l}45 \cdot 1 \\
54 \cdot 9\end{array}$ \\
\hline \multicolumn{9}{|l|}{ Grade level } \\
\hline 5 & 111 & $27 \cdot 8$ & 129 & $27 \cdot 4$ & 112 & $27 \cdot 5$ & 352 & $27 \cdot 6$ \\
\hline 6 & 137 & $34 \cdot 2$ & 131 & $27 \cdot 9$ & 140 & $34 \cdot 4$ & 408 & $31 \cdot 9$ \\
\hline 7 & 62 & $15 \cdot 5$ & 107 & $22 \cdot 8$ & 72 & $17 \cdot 7$ & 241 & $18 \cdot 9$ \\
\hline 8 & 90 & $22 \cdot 5$ & 103 & $21 \cdot 9$ & 83 & $20 \cdot 4$ & 276 & $21 \cdot 6$ \\
\hline \multicolumn{9}{|l|}{ Language spoken at home } \\
\hline English & 212 & $53 \cdot 0$ & 282 & $60 \cdot 0$ & 200 & $49 \cdot 1$ & 694 & $54 \cdot 3$ \\
\hline French & 56 & $14 \cdot 0$ & 42 & 8.9 & 54 & $13 \cdot 3$ & 152 & $11 \cdot 9$ \\
\hline Both English and French & 129 & $32 \cdot 2$ & 142 & $30 \cdot 2$ & 148 & $36 \cdot 4$ & 419 & $32 \cdot 8$ \\
\hline \multirow[t]{2}{*}{ Others } & 3 & $0 \cdot 8$ & 4 & 0.9 & 5 & $1 \cdot 2$ & 12 & 0.9 \\
\hline & \multicolumn{2}{|c|}{$n 213$} & \multicolumn{2}{|c|}{$n 228$} & \multicolumn{2}{|c|}{ n 254} & \multicolumn{2}{|c|}{$n 695$} \\
\hline $\begin{array}{l}\text { Total fruit and vegetable } \\
\text { intake at baseline } \\
\text { (mean (sD)) }\end{array}$ & $4 \cdot 2$ & $3 \cdot 2$ & $4 \cdot 7$ & $3 \cdot 2$ & $4 \cdot 8$ & $3 \cdot 3$ & - & - \\
\hline
\end{tabular}

No statistical significant difference was detected by $\chi^{2}$ test among the three intervention arms.

Table 3 Participants' opinion on receiving free fruit and vegetables (\%)

\begin{tabular}{|c|c|c|c|c|c|c|}
\hline & \multicolumn{2}{|c|}{ Intervention I ( $n$ 400) } & \multicolumn{2}{|c|}{ Intervention II ( $n$ 470) } & \multicolumn{2}{|c|}{ Control group ( $n$ 407) } \\
\hline & Baseline (\%) & Endpoint (\%) & Baseline (\%) & Endpoint (\%) & Baseline (\%) & Endpoint (\%) \\
\hline \multicolumn{7}{|l|}{ Fruit } \\
\hline Like & 88 & 84 & 86 & 84 & 83 & 84 \\
\hline Neutral & 11 & 13 & 12 & 13 & 15 & 12 \\
\hline Dislike & 2 & 3 & 3 & 2 & 3 & 4 \\
\hline \multicolumn{7}{|l|}{ Vegetables } \\
\hline Like & 74 & 74 & 69 & 68 & 62 & 64 \\
\hline Neutral & 22 & 18 & 24 & 23 & 27 & 23 \\
\hline Dislike & 5 & 9 & 8 & 9 & 11 & 13 \\
\hline
\end{tabular}

No statistical significant difference was detected by $\chi^{2}$ test between baseline and endpoint.

Table 4 Intervention effect on fruit and vegetable intake (mean and SE)*

\begin{tabular}{|c|c|c|c|c|c|c|c|}
\hline \multirow[b]{2}{*}{ Fruit and vegetable intake (servings/dt) } & \multicolumn{2}{|c|}{ Intervention I ( $n$ 213) } & \multicolumn{2}{|c|}{ Intervention II (n 228) } & \multicolumn{2}{|c|}{ Control group ( $n$ 254) } & \multirow[b]{2}{*}{$P$} \\
\hline & Mean & SE & Mean & SE & Mean & SE & \\
\hline Fruit and vegetables at school & $1 \cdot 9$ & $0 \cdot 1^{a}$ & $1 \cdot 8$ & $0 \cdot 2^{a b}$ & $1 \cdot 4$ & $0 \cdot 2^{b}$ & $<0.05$ \\
\hline Fruit and vegetables at home & $2 \cdot 5$ & 0.2 & $2 \cdot 5$ & $0 \cdot 2$ & $2 \cdot 4$ & $0 \cdot 3$ & $>0.05$ \\
\hline Total fruit and vegetables (home + school) & $4 \cdot 4$ & $0 \cdot 2$ & $4 \cdot 3$ & $0 \cdot 3$ & $3 \cdot 8$ & $0 \cdot 4$ & $>0.05$ \\
\hline
\end{tabular}

$\overline{a, b}$ Means with different superscript letters are significantly different by post hoc multiple comparison using the least significant difference (LSD) pairwise multiple comparison.

${ }^{*}$ Means are adjusted for baseline measures, age and gender as covariates, and school clustering effect, school location (urban $v$. rural) and presence of existing fruit and vegetable programmes as random factors.

tSubjects with missing values were excluded from the analysis.

difference was not statistically significant. Only a very slight difference existed between Intervention I and II (Fig. 2).

\section{Secondary outcomes - psychosocial and}

behavioural scales

Students' psychosocial and behavioural scores at endpoint are presented in Table 5. Mean scores on the knowledge, attitude, liking, intention, willingness and peer-influence scales were close to the maximum values, implying that students across the three groups had high knowledge levels, positive attitudes about fruit and vegetables and enjoyed, intended to consume and were willing to try fruit and vegetables. In addition, there was a positive peer influence around fruit and vegetable consumption. Students from all three groups had moderate levels of self-efficacy and habits to consume fruit and vegetables. The preference scores on the twenty fruit and twenty-three vegetables listed were relatively low. There were no statistically significant differences among the three groups for all scores, except that 


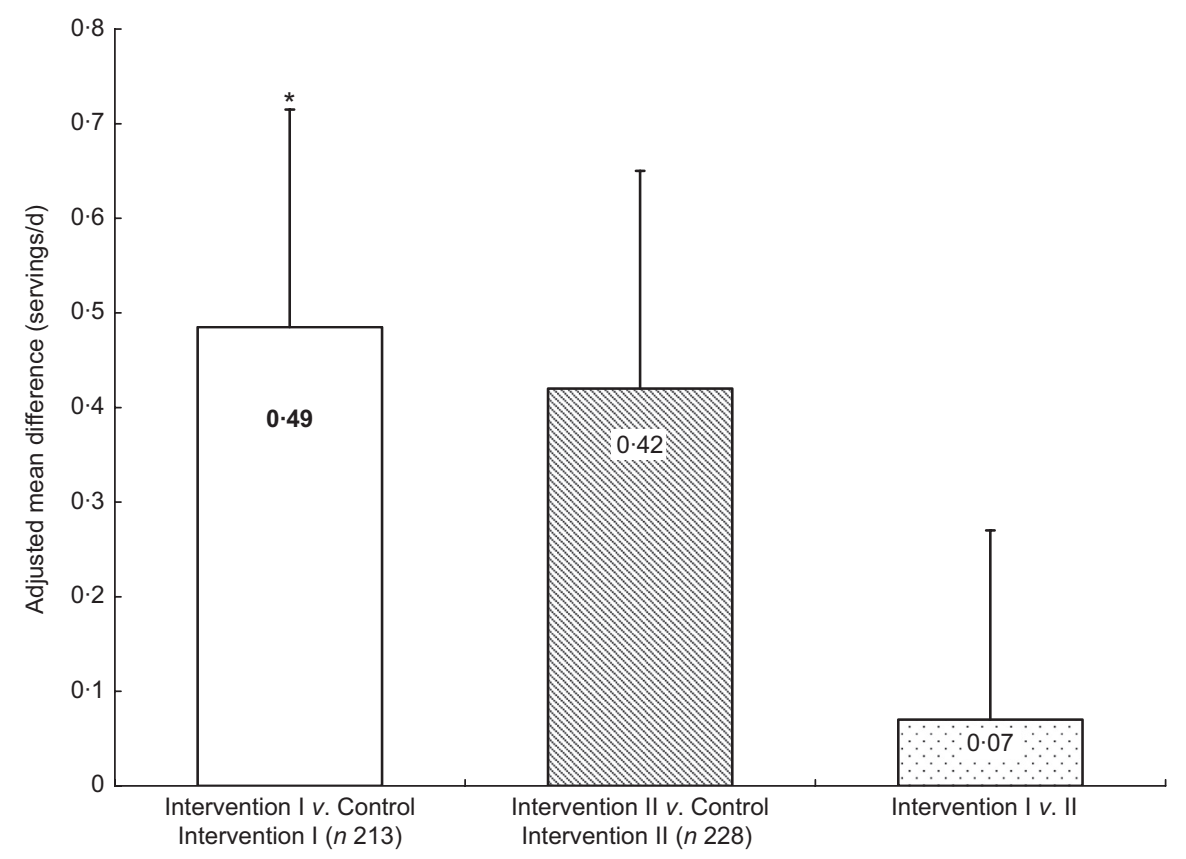

Fig. 2 Intervention effects on fruit and vegetable intake at school. Adjusted mean differences and standard errors of fruit and vegetable intake at school (serving/school day) between groups, controlling for baseline measure, age and gender as covariates, and school clustering effect, school location (urban $v$. rural) and presence of existing fruit and vegetable programmes as random factors. *Intervention I mean values were significantly different from those in the Control group: $P<0.05$ by post hoc multiple comparison using the least significant difference (LSD) pairwise comparison

Intervention I and II seemed to have slightly higher preference scores than the Control group.

Comparing students' responses to each of the psychosocial and behavioural questions at baseline and endpoint, it was noted that students' preferences for certain fruit and vegetables shifted from 'never tried it' towards 'like it' (Table 6). In Intervention I, the proportion of students who had 'never tried' cauliflower decreased from $17 \%$ at baseline to $7 \%$ at endpoint, while the proportion of students who 'liked' cauliflower increased from $54 \%$ at baseline and $63 \%$ at endpoint $\left(\chi^{2}=24, P<0 \cdot 05\right)$. Students in Intervention II had statistically significant shifts in their preferences for apple sauce, peach cups, leeks, cauliflower and rutabaga from 'never tried it' towards 'like it'. Although the students in the Control group also showed statistically significant changes in their preferences for peach cups and cauliflower, the shifts were bidirectional (i.e. some 'never tried' responses shifted to 'like it' and some to 'dislike it'). In contrast, there was a tendency toward unfavourable changes in self-efficacy, intention and peer influence related to vegetable consumption in Intervention II students at endpoint, but not in Intervention I or Control group students (Fig. 3). The proportion of students in Intervention II who 'agreed' to the intention statement, 'I want to eat vegetables' decreased from $74 \%$ at baseline to $70 \%$ at endpoint $\left(\chi^{2}=8 \cdot 3, \quad P<0 \cdot 05\right)$. Similarly, at baseline, $83 \%$ of students felt that 'If I decided to eat vegetables, I can do it' (a self-efficacy measure); this percentage decreased to $76 \%$ at endpoint $\left(\chi^{2}=9 \cdot 7, P<0 \cdot 05\right)$. The proportion of students who perceived that 'my best friend(s) eat vegetables', a measure of peer-influence, decreased from $55 \%$ at baseline to $46 \%$ at endpoint $\left(\chi^{2}=9 \cdot 5, P<0 \cdot 05\right)$.

\section{Discussion}

The NFVPP's impact was evaluated using a non-blinded, cluster-RCT with validated instruments that are sensitive for assessing intervention effects ${ }^{(12,13)}$. Based on our knowledge of the relevant literature, this is the first largescale Canadian healthy eating promotion initiative to be evaluated using a scientifically rigorous method. Our results indicate that the NFVPP increased fruit and vegetable consumption at school among children in grades five to eight and resulted in favourable preference changes towards certain fruit and vegetables.

Intervention I students consumed significantly more fruit and vegetables at school by 0.49 serving/d, as compared to the Control group. Although not statistically significant in comparison to the Control group, Intervention I and II resulted in increases in subjects' total daily fruit and vegetable intake by 0.6 and 0.5 serving, respectively. These results are consistent with the "5-a-Day Power Plus Program' in Minnesota, which increased fruit and vegetable consumption at lunch by $0 \cdot 4$ serving $/ \mathrm{d}^{(17)}$. The school-based intervention in Minnesota employed multiple strategies including behavioural curricula in classrooms, parental involvement, school food service changes and industry support and involvement. The authors concluded 
Table 5 Intervention effect on psychosocial variables and behavioral outcomes

\begin{tabular}{|c|c|c|c|c|c|c|c|c|c|c|}
\hline \multirow[b]{2}{*}{ Variables } & \multirow[b]{2}{*}{ Items } & \multirow[b]{2}{*}{ Cronbach $\alpha$} & \multirow[b]{2}{*}{ Possible range } & \multicolumn{2}{|c|}{ Intervention I } & \multicolumn{2}{|c|}{ Intervention II } & \multicolumn{2}{|c|}{ Control group } & \multirow[b]{2}{*}{$P$} \\
\hline & & & & Mean & SE & Mean & SE & Mean & SE & \\
\hline $\begin{array}{l}\text { Knowledge } \\
\text { How many servings of fruit and vegetables } \\
\text { do you think you should eat everyday to } \\
\text { stay healthy? }\end{array}$ & 1 & $\mathrm{~N} / \mathrm{A}$ & $\mathrm{N} / \mathrm{A}$ & $5 \cdot 1$ & $0 \cdot 2$ & $5 \cdot 0$ & 0.2 & $4 \cdot 8$ & $0 \cdot 2$ & $>0.05$ \\
\hline $\begin{array}{l}\text { Attitude (fully disagree } \rightarrow \text { fully agree) } \\
\text { Eating fruit/vegetables every day makes } \\
\text { me feel good } \\
\text { Eating fruit/vegetables every day gives me } \\
\text { more energy } \\
\text { Eating fruit and vegetables could help } \\
\text { prevent heart disease }\end{array}$ & 5 & $0 \cdot 76$ & $5-25$ & $21 \cdot 6$ & $0 \cdot 3$ & $21 \cdot 4$ & $0 \cdot 2$ & $21 \cdot 5$ & $0 \cdot 3$ & $>0.05$ \\
\hline $\begin{array}{l}\text { Liking (fully disagree } \rightarrow \text { fully agree) } \\
\text { I like to eat fruit/vegetables every day } \\
\text { Fruit/vegetables tastes good }\end{array}$ & 4 & 0.79 & $4-20$ & $16 \cdot 8$ & $0 \cdot 2$ & $17 \cdot 0$ & $0 \cdot 2$ & $16 \cdot 8$ & $0 \cdot 2$ & $>0.05$ \\
\hline $\begin{array}{l}\text { Self-efficacy } \\
\text { It is difficult for me to eat fruit/vegetables } \\
\text { every day (fully agree } \rightarrow \text { fully disagree) } \\
\text { If I decide to eat fruit/vegetables every } \\
\text { day, I can do it (fully disagree } \rightarrow \text { fully } \\
\text { agree) }\end{array}$ & 4 & 0.64 & $4-20$ & $16 \cdot 0$ & $0 \cdot 3$ & $16 \cdot 0$ & $0 \cdot 2$ & $15 \cdot 8$ & $0 \cdot 3$ & $>0.05$ \\
\hline $\begin{array}{l}\text { Intention (fully disagree } \rightarrow \text { fully agree) } \\
\text { I want to eat fruit/vegetables every day }\end{array}$ & 2 & 0.66 & $2-10$ & $8 \cdot 4$ & $0 \cdot 1$ & $8 \cdot 3$ & $0 \cdot 1$ & $8 \cdot 3$ & $0 \cdot 1$ & $>0.05$ \\
\hline $\begin{array}{l}\text { Willingness (not willing } \rightarrow \text { very willing) } \\
\text { How willing are you to try a fruit/vegetable } \\
\text { that you've never tried before? }\end{array}$ & 2 & $0 \cdot 74$ & $2-8$ & $6 \cdot 3$ & $0 \cdot 1$ & $6 \cdot 4$ & $0 \cdot 1$ & $6 \cdot 4$ & $0 \cdot 1$ & $>0.05$ \\
\hline $\begin{array}{l}\text { Habits (fully disagree } \rightarrow \text { fully agree) } \\
\text { Eating fruit every day is a habit for me } \\
\text { I usually ask my parents to buy fruit and } \\
\text { vegetables } \\
\text { I usually bring fruit/vegetables to school }\end{array}$ & 6 & $0 \cdot 82$ & $6-30$ & $21 \cdot 7$ & $0 \cdot 4$ & $22 \cdot 2$ & $0 \cdot 3$ & $21 \cdot 8$ & $0 \cdot 3$ & $>0.05$ \\
\hline $\begin{array}{l}\text { Preferences (dislike } \rightarrow \text { like) } \\
\text { Which of the following fruits do you like or } \\
\text { dislike ( } 20 \text { fruits and } 23 \text { vegetables) }\end{array}$ & 43 & 0.94 & $43-215$ & $118 \cdot 0$ & $0 \cdot 15$ & $118 \cdot 1$ & $0 \cdot 11$ & $116 \cdot 3$ & $0 \cdot 14$ & $>0.05$ \\
\hline $\begin{array}{l}\text { Peer influences (disagree } \rightarrow \text { fully agree) } \\
\text { My best friends eat fruit/vegetables }\end{array}$ & 2 & $0 \cdot 78$ & $2-10$ & $7 \cdot 2$ & $0 \cdot 2$ & $7 \cdot 3$ & $0 \cdot 1$ & $7 \cdot 3$ & $0 \cdot 1$ & $>0.05$ \\
\hline
\end{tabular}

Means are adjusted for baseline measures, age and gender as covariates, and school clustering effect and presence of existing fruit and vegetable programmes as random factors.

Table 6 Changes in fruit and vegetable preferences: baseline $v$. endpoint

\begin{tabular}{|c|c|c|c|c|c|c|c|c|c|}
\hline & \multicolumn{3}{|c|}{ Intervention I (n 378) } & \multicolumn{3}{|c|}{ Intervention II (n 441) } & \multicolumn{3}{|c|}{ Control group ( $n$ 393) } \\
\hline & Like & Never tried & Dislike & Like & Never tried & Dislike & Like & Never tried & Dislike \\
\hline \multicolumn{10}{|l|}{ Rutabaga } \\
\hline Baseline & 15 & 62 & 24 & 12 & 71 & 17 & 22 & 57 & 21 \\
\hline $\begin{array}{l}\text { Endpoint } \\
P \text { value }\end{array}$ & 21 & $\begin{aligned} & 55 \\
> & 0.05\end{aligned}$ & 23 & 15 & $\begin{array}{c}68 \\
<0.01\end{array}$ & 18 & 21 & $\begin{aligned} & 59 \\
> & 0.05\end{aligned}$ & 21 \\
\hline \multicolumn{10}{|l|}{ Cauliflower } \\
\hline Baseline & 54 & 17 & 29 & 57 & 17 & 26 & 59 & 16 & 25 \\
\hline $\begin{array}{l}\text { Endpoint } \\
P \text { value }\end{array}$ & 63 & $\begin{array}{c}7 \\
<0.05\end{array}$ & 29 & 70 & $\begin{array}{c}6 \\
<0.01\end{array}$ & 24 & 62 & $\begin{array}{c}9 \\
<0.01\end{array}$ & 29 \\
\hline \multicolumn{10}{|l|}{ Leeks } \\
\hline Baseline & 21 & 58 & 21 & 17 & 65 & 18 & 32 & 45 & 24 \\
\hline Endpoint & 28 & 51 & 21 & 22 & 60 & 18 & 26 & 47 & 27 \\
\hline$P$ value & & $>0.05$ & & & $<0.05$ & & & $>0.05$ & \\
\hline \multicolumn{10}{|l|}{ Peach cup } \\
\hline Baseline & 71 & 6 & 23 & 70 & 8 & 22 & 73 & 10 & 17 \\
\hline Endpoint & 78 & 3 & 19 & 75 & 4 & 20 & 75 & 4 & 20 \\
\hline$P$ value & & $>0.05$ & & & $<0.01$ & & & $<0.01$ & \\
\hline \multicolumn{10}{|l|}{ Apple sauce } \\
\hline Baseline & 60 & 10 & 30 & 58 & 9 & 33 & 61 & 13 & 26 \\
\hline $\begin{array}{l}\text { Endpoint } \\
P \text { value }\end{array}$ & 67 & $\begin{array}{c}5 \\
>0.05\end{array}$ & 28 & 65 & $\begin{array}{c}7 \\
<0.05\end{array}$ & 28 & 61 & $\begin{array}{c}9 \\
>0.05\end{array}$ & 31 \\
\hline
\end{tabular}




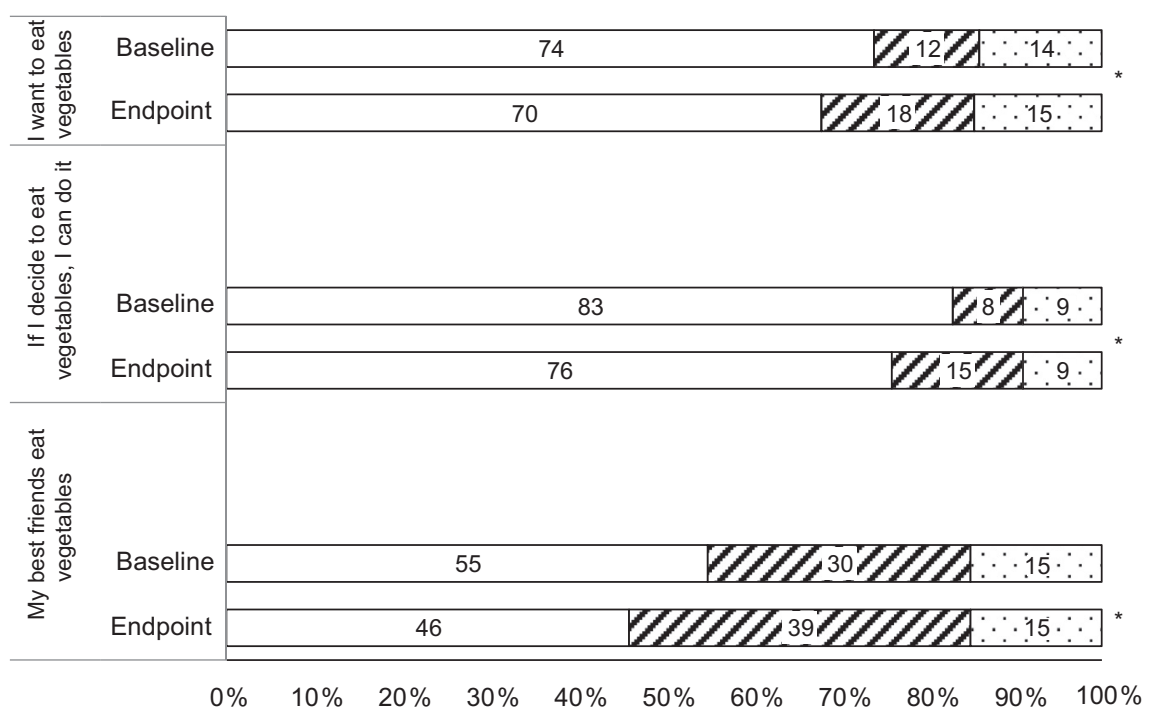

Fig. 3 Psychosocial variable changes in Intervention II - baseline $v$. endpoint ( $\square$, agree; $\mathbb{Z}$, neutral; $\because$, disagree) ${ }^{\star} P<0 \cdot 05$ by $\chi^{2}$ test

that parental involvement is needed to increase fruit and vegetable consumption at home ${ }^{(17)}$. In the NFVPP, the insignificant changes in fruit and vegetable consumption at home may be attributed to minimal parental involvement coupled with the community's limited access to fresh fruit and vegetables.

An important question to be addressed was 'did the combination of distributing free fruit and vegetables with enhanced nutrition education result in a greater impact on children's fruit and vegetable consumption than distributing free fruit and vegetables alone?' A recent study by Reinaerts et al. examined the effect of a free fruit and vegetable distribution programme compared to a multicomponent programme consisting of curriculum and parental involvement on 4-12 year-old children's fruit and vegetable consumption ${ }^{(18)}$. Both programmes increased children's consumption by $0 \cdot 2$ serving/d, suggesting that merely distributing free fruit and vegetables has potential as a practical population-based strategy to increase children's fruit and vegetable intake ${ }^{(18)}$. Our current evaluation compared the net intervention effect between two interventions. Although no statistical differences were detected between the intervention arms, the combined strategy, but not the FFVS-alone strategy, resulted in significant increases in children's fruit and vegetable consumption at school. This finding implies that the combined strategy worked better than the single strategy, despite the fact that the ENE component was not implemented fully ${ }^{(11)}$.

It is important to consider how the NFVPP results compare to other published research. In a systematic review of eleven fruit and vegetable interventions among elementary-school students, nine had a significant positive effect on fruit and vegetable consumption ${ }^{(19)}$. The review highlighted key features that facilitated the interventions' success, including: duration of at least
12 months; increased fruit and vegetable exposure in the school community; inclusion of teacher training and integration into the curriculum; leadership and encouragement by peers and school food service staff; and involvement of parents at school and at home ${ }^{(19)}$. The NFVPP possessed a number of these features; however, due to the pilot nature of the programme, the ENE component was not implemented fully, and the restricted variety of fruit and limited capacity to deliver fresh vegetables to schools in remote Northern areas may have further compromised intervention effects ${ }^{(11)}$.

Although no differences were detected in any psychosocial or behavioural scores across the three groups, there were favourable preference changes on certain fruit and vegetables with a shift from 'never tried it' towards 'like it' in Intervention I and II students. This finding echoes that of a fruit and vegetable intervention in Prince Edward Island (Canada) that demonstrated an increase in elementaryschool students' liking of certain fruit and vegetables after a 6-week exposure period ${ }^{(20)}$. Another study reported that when children were exposed to sweet peppers for 2 weeks, their 'liking' of the vegetable increased significantly as compared to a Control group ${ }^{(21)}$. The authors suggested that 'exposure' has promise as a technique for improving children's liking of vegetables ${ }^{(21)}$. In the current context, more children in Intervention I and II 'liked' cauliflower after the intervention. Surprisingly, children in Intervention II began liking vegetables (e.g. leeks and rutabaga) that were not offered in the programme. Based on Social Cognitive Theory's underlying principle of reciprocal determinism, people's behaviour influences, and is influenced by, personal factors as well as the social and physical environment ${ }^{(22)}$. Research suggests that children's dislike of foods can be transformed into liking with repeated tasting or 'exposure' to those foods ${ }^{(23)}$. It is speculated that 
children in the NFVPP became more apt to try and 'like' new fruit and vegetables through exposure to fruit and vegetables in school. In addition, research has shown that children's preferences for, and consumption of, disliked vegetables improved when children had opportunities to observe their peers selecting and eating those foods, and were encouraged by adults to try new foods ${ }^{(24)}$. The current intervention afforded children the opportunity to learn from their peers and be encouraged by teachers in this regard; therefore, it is unclear why this phenomenon was not observed in the Intervention I group. In the Control group, children's preferences for cauliflower and peach cups shifted significantly, from 'never tried' to both 'liked' and 'disliked'. This phenomenon may have come as a result of children's enhanced willingness to try new foods as they age. Observed differences in children's preferences must be interpreted with caution, because it cannot be determined whether they were a result of receiving the NFVPP or other events such as history, maturation and testing. Unlike the previous analyses, this type of single group pre-post analysis does not control for these threats to validity. Future research should further examine these trends to determine if preference changes are artefacts or attributable to the intervention.

Avoiding unintended adverse outcomes is critical, especially for population-based interventions. There appears to be minor undesirable intervention outcomes in the NFVPP, consisting of a tendency towards unfavourable changes in self-efficacy, intention and peer influence pertaining to vegetable consumption among students in Intervention II. Such adverse outcomes may be attributed to exposure to poor quality vegetables. However, students in both Intervention I and II were exposed to the same vegetables including those of poor quality ${ }^{(11)}$. It is speculated that Intervention I's ENE component may have prevented these adverse outcomes; however, further research is needed to determine how the unfavourable outcomes may be prevented. These results suggest that in order to minimise unintended adverse outcomes on children's psychosocial variables and behaviours, future fruit and vegetable programmes need to ensure full implementation of the ENE, increase variety over a longer duration, involve parents and further engage teachers and staff in the implementation process.

The NFVPP used a combined strategy (FFVS + ENE) which demonstrated a favourable intervention effect on children's fruit and vegetable consumption at school, despite numerous methodological challenges and limitations ${ }^{(11)}$. The pre-coded $24 \mathrm{~h}$ recall questionnaire is considered to have acceptable validity and reliability, and is suitable for use in reflecting relatively small intervention effect sizes ${ }^{(12)}$. Due to the tight timeline for baseline data collection before the launch of this government-funded initiative, the research team was unable to pre-test the European-based instrument among a sample of children in Ontario, Canada. The questionnaire is also relatively complicated to complete, which may have resulted in a substantial proportion of missing and invalid values. Although the overall sample size was close to the 437 subjects per group that was required to detect an intervention effect of 0.4 serving/d (with power of $80 \%$; type one error of $5 \%$ ), the missing/invalid values decreased the sample size. This compromised the statistical power when determining the intervention effects on fruit and vegetable consumption. In addition, while methods for analysing continuous outcomes are well established for cluster-RCT, there is currently a limited capacity for analysing categorical data with commonly used statistical software (e.g. SPSS) ${ }^{(25)}$. Therefore, results from the pre- and post-changes in categorical variables should be interpreted with caution.

\section{Conclusions and implications}

The NFVPP resulted in positive changes in elementary school-aged children's fruit and vegetable consumption at school, and favourable preference changes for certain fruit and vegetables. Future fruit and vegetable programmes should consider using a combined strategy of both nutrition education and exposure to fruit and vegetables, and improving community access to affordable fresh fruit and vegetables where necessary.

The current study was a pilot project aimed at providing insights to inform effective health promotion programme delivery. Recommendations for the Ontario Ministry of Health Promotion include, but are not limited to: (i) continue the Northern Fruit and Vegetable Programme having addressed issues related to produce quality; (ii) use a combined strategy that offers free fruit and vegetables and enhanced nutrition education in the classroom; (iii) allocate funds to examine, at a population level, the programme's long-term impact on children's fruit and vegetable consumption.

\section{Acknowledgements}

There is no conflict of interest in this submission. The Ontario Ministry of Health Promotion (MHP) funded the project. The authorship responsibilities are as follows: M.H. and C.B. co-led the research project and made significant intellectual contributions to study design, survey instrument selection, sampling strategy and the analysis and interpretation of data associated with the work contained in the manuscript. L.K. made substantial contributions to the project in her role as the evaluation project coordinator. M.H. drafted the article and C.B. reviewed and revised it for intellectual content. M.S.B., R.S.O., S.S., L.K., B.A.H. and B.C. participated in the process of survey instrument selection, data interpretation, and review and revision of the manuscript for intellectual content. All authors approved the contents of the manuscript. The authors are most appreciative of 
the support of Ms Roselle Martino, Nutrition Consultant, Chronic Disease Prevention and Health Promotion Branch (MHP) and her ministry colleagues for their support of the PHRED Programme. The authors are grateful to Ms Melissa van Zandvoort, Research Associate, Public Health Research, Education and Development (PHRED) Programme, Middlesex-London Health Unit for revising and formatting the draft manuscript; as well as Ms Nancy Forbes and Ms Susie Noble, Middlesex-London Health Unit, for their continued support throughout the research project. Appreciation is also extended to the Work-Study Programme at Brescia University College for providing salary support to the students who assisted with data entry and verification. The evaluation would not have been possible without the active engagement and commitment of many players. Special thanks go to school principals and teachers for their assistance in the informed consent process and data collection.

\section{References}

1. Shields M (2006) Overweight and obesity among children and youth. Health Rep 17, issue 3, 27-42.

2. Maynard LM, Galuska DA, Blanck HM \& Serdula MK (2003) Maternal perceptions of weight status of children. Pediatrics 111, 1226-1231.

3. Ness AR, Maynard M, Frankel S, Davey Smith G, Frobisher C, Leary SD, Emmett PM \& Gunnell D (2005) Diet in childhood and adult cardiovascular and all cause mortality: the Boyd Orr cohort. Heart 91, 894-898.

4. Health Canada (2007) Canada's Food Guide: How Many Food Guide Servings of Fruit and Vegetables Do I Need? http://www.hc-sc.gc.ca/fn-an/food-guide-aliment/choosechoix/fruit/need-besoin-eng.php (accessed May 2009).

5. Garriguet D (2006) Overview of Canadians' Eating Habits. Nutrition: Findings from the Canadian Community Health Survey. Report no. 82-620-MIE - No. 2. Ottawa, ON: Statistics Canada.

6. Krebs-Smith SM, Heimendinger J, Patterson BH, Subar AF, Kessler R \& Pivonka E (1995) Psychosocial factors associated with fruit and vegetable consumption. Am J Health Promot 10, 98-104.

7. Kelder SH, Perry CL, Klepp KI \& Lytle LL (1994) Longitudinal tracking of adolescent smoking, physical activity, and food choice behaviors. Am J Public Health 84, 1121-1126.

8. Lien N, Lytle LA \& Klepp KI (2001) Stability in consumption of fruit, vegetables, and sugary foods in a cohort from age 14 to age 21. Prev Med 33, 217-226.

9. Sharma M (2006) School-based interventions for childhood and adolescent obesity. Obes Rev 7, 261-269.
10. United States of America (2007) Richard B. Russell National School Lunch Act, 2007. Washington, DC: Senate and House of Representatives of the United States of America.

11. Sangster Bouck M, St Onge R, He M, Beynon C, Lemieux S, Khoshaba L \& Stewart S (2008) Process evaluation of a school-based fruit and vegetable program. Can J Diet Pract Res (submitted).

12. Haraldsdottir J, Thorsdottir I, de Almeida MD, Maes L, Perez RC, Elmadfa I \& Frost AL (2005) Validity and reproducibility of a precoded questionnaire to assess fruit and vegetable intake in European 11- to 12-year-old schoolchildren. Ann Nutr Metab 49, 221-227.

13. De Bourdeaudhuij I, Klepp KI, Due P, Rodrigo CP, de Almeida M, Wind M, Krolner R, Sandvik C \& Brug J (2005) Reliability and validity of a questionnaire to measure personal, social and environmental correlates of fruit and vegetable intake in 10-11-year-old children in five European countries. Public Health Nutr 8, 189-200.

14. Dole 5 A Day Program (2007) 5 A Day Facts: Fruit \& Vegetable Nutrition Facts Chart. http://216.255.136.121/ReferenceCenter/ NutritionCenter/Chart/R_NutrChart.jsp (accessed May 2009).

15. Michels KB, Edward G, Joshipura KJ, Rosner BA, Stampfer MJ, Fuchs CS, Colditz GA, Speizer FE \& Willett WC (2000) Prospective study of fruit and vegetable consumption and incidence of colon and rectal cancers. J Natl Cancer Inst 92, 1740-1752.

16. Garriguet D (2007) Canadians' eating habits. Health Rep 18, issue 2, 17-32.

17. Perry CL, Bishop DB, Taylor G, Murray DM, Mays RW, Dudovitz BS, Smyth M \& Story M (1998) Changing fruit and vegetable consumption among children: the 5-a-Day Power Plus program in St. Paul, Minnesota. Am J Public Health 88, 603-609.

18. Reinaerts E, de NJ, Candel M \& de Vries N (2007) Increasing children's fruit and vegetable consumption: distribution or a multicomponent programme? Public Health Nutr 10, 939-947.

19. Knai C, Pomerleau J, Lock K \& McKee M (2006) Getting children to eat more fruit and vegetables: a systematic review. Prev Med 42, 85-95.

20. Taylor J \& Binns D (2003) Evaluation of a Fruit \& Vegetable Pilot Program for Elementary School Children in Prince Edward Island. Prince Edward Island: Prince Edward Island Healthy Eating Alliance.

21. Wardle J, Herrera ML, Cooke L \& Gibson EL (2003) Modifying children's food preferences: the effects of exposure and reward on acceptance of an unfamiliar vegetable. Eur J Clin Nutr 57, 341-348.

22. Bandura A (1986) Social Foundation of Thought and Action: a Social Cognitive Theory. Englewood Cliffs, NJ: Prentice-Hall.

23. Drewnowski A (1997) Taste preferences and food intake. Annu Rev Nutr 17, 237-253.

24. Birch LL (1999) Development of food preferences. Annu Rev Nutr 19, 41-62.

25. Dobbins TA \& Simpson JM (2002) Comparison of tests for categorical data from a stratified cluster randomized trial. Stat Med 21, 3835-3846. 